\section{$\underset{\text { hommes }}{\text { \& migrations }}$}

\section{Hommes \& migrations}

Revue française de référence sur les dynamiques

migratoires

1335 | 2021

Saisir le murmure du monde

\title{
Jeux de miroirs
}

Marianne Amar

\section{(2) OpenEdition \\ Journals}

Édition électronique

URL : https://journals.openedition.org/hommesmigrations/13314

DOI : 10.4000/hommesmigrations.13314

ISSN : 2262-3353

\section{Éditeur}

Musée national de l'histoire de l'immigration

\section{Édition imprimée}

Date de publication : 1 octobre 2021

Pagination : 82-83

ISBN : 978-2-919040-59-9

ISSN : $1142-852 X$

\section{Référence électronique}

Marianne Amar, « Jeux de miroirs », Hommes \& migrations [En ligne], 1335 | 2021, mis en ligne le 01 octobre 2021, consulté le 26 février 2022. URL : http://journals.openedition.org/hommesmigrations/ 13314 ; DOI : https://doi.org/10.4000/hommesmigrations.13314 


\section{PORTFOLIO}

\section{Jeux de miroirs}

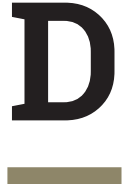

ans leurs silences et leurs absences, dans la tension toujours à vif entre le cadre et son hors-champ, dans la mélancolie de ce qui n'est plus et la présence singulière du passé dans le présent, «dans l'évidence trompeuse de leur noir et blanc $^{1} \gg$, quel récit visuel construisent les photographies de migration de l'entre-deux-guerres? Ou plutôt, que peut la photographie pour faire récit de soi en migration? Avant d'entrer dans les collections du Musée comme on feuillette un album de famille, on voudrait ouvrir des pistes de réflexion pour instituer, par les questionnements qu'on lui adresse, la photographie de/en migration comme un document, au-delà de son statut convenu d'œuvre ou d'illustration.

Au studio ou dans l'intimité des familles, avec ou sans contraintes, ce qui se donne en premier dans ces images, en tout cas le plus aisé à saisir, c'est leur capacité à « incarner », à proposer des migrations un récit sensible, à travers l'humanité des visages et des corps, loin des seules logiques statistiques et collectives. Font-ils pour autant récit de soi, ces portraits captés dans le studio, parfois dans la rue ou des espaces privés, et toujours contraints par les règles de la pose? Sans doute, si l'on sait observer le rapport à la norme et les postures du corps. Dans le studio, comme partout ailleurs, on pose avec raideur et solennité, en fixant droit l'objectif. Les vêtements et la mise en scène trahissent parfois les pratiques du pays d'origine, mais s'imposent surtout la soumission aux codes de la société d'accueil et la volonté d'attester d'une intégration sociale en marche, à travers l'intégration dans un système de représentation. Le portrait et ses postures contrôlées permettent aussi aux migrants de reprendre symboliquement le contrôle de leur corps, trop souvent contraint et usé par le travail. Les photographies de sportifs, si nombreuses dans l'entre-deux-guerres, disent ainsi cette fierté des corps redressés. En groupe, leur manière de «faire corps » collectivement constitue « un acte de célébration et de renforcement de l'unité de groupe qui assure son droit à l'existence dans la société française ${ }^{2} \gg$. Dans tous les cas, à travers ces photographies, « on se donne à regarder comme on entend être regardé, on donne l'image de soi ${ }^{3}$ ».

Les photographies d'identité participent aussi, dans les interstices laissés par les textes administratifs, de ce récit de soi. Collées, agrafées sur des documents administratifs qui doivent être des doubles de soi normalisés, elles laissent parfois échapper des bribes d'intimité ou de vérité. Une coiffe, un chapeau, quand la règle exige de poser tête nue. Des enfants sur les genoux de leur mère, et l'empreinte floue qu'ils laissent sur la gélatine, trop impatients pour rester immobiles. L'urgence conduit parfois à jeter par-dessus bord

1. George Perec, Robert Bober, Récits d'Ellis Island. Histoires d'errance et d'espoir, Paris, P.O.L/Institut national de l'audiovisuel, 1994, p. 37.

2. Michelle Zancarini-Fournel, « Usages de la photographie et immigration : de l'identification à l'intégration. Le photographe des Ponts-Saint-Étienne 1917-1950», in La trace. Cahiers du CEDEI, n 5, 1991, p. 25.

3. Pierre Bourdieu (dir.), Un art moyen. Essai sur les usages sociaux de la photographie, Paris, éd. de Minuit, 1965, p. 120. 
toutes les règles. En témoignent, par exemple, les demandes de visa déposées auprès des consulats français à Bucarest ou à Kaunas par des Polonais réfugiés après la défaite de leur pays à l'automne 1939. Certaines photographies respectent les normes, mais nombre de réfugiés ont agrafé ce qui leur restait. Des photographies arrachées à un ancien document administratif devenu inutile, qui gardent la trace de la vie d'avant, mais redécoupées puis recollées sur la demande de visa, comme on tente de recoller les morceaux d'une vie pour lui conserver tout son sens. Des portraits de famille aussi, transformés, transfigurés par un nouvel usage: des femmes, des enfants, des hommes, qui sourient à l'objectif, parfois enlacés, d'autres endimanchés. Quelques-uns font les pitres, des femmes jouent les divas, mais au présent, on y " voit » autre chose : un monde enfui qui ne reviendra pas ; leur sort à venir, si souvent funeste. Ainsi, par leur force d'évocation, ces petits rectangles de papier tiennent trois récits entrelacés - récit intime du passé, présent de l'exil, tragédie à venir. La troisième piste à creuser ressort de l'illusion de vérité portée par ces photographies. Car si elles sont bel et bien construites à partir du réel, elles ne cessent de le subvertir par le cadrage et les diverses formes de mise en scène: les récits de soi photographiques sont souvent tissés de mensonges. Le monde de la boutique apparaît à cet égard exemplaire. $\mathrm{Au}$ cours du premier $\mathrm{XX}^{\mathrm{e}}$ siècle, le commerce communautaire qui donne à voir l'altérité - produits ethniques, noms étrangers à leur fronton - tient souvent de «l'évidence trompeuse ». Car bien des commerçants ne cherchent à, ni ne veulent afficher leur origine. Ils préfèrent mettre en valeur des arguments économiques - efficacité, nouveauté, prix et, si nécessaire, ils s'inscrivent visuellement dans l'univers de référence le mieux adapté à leur produit 4 . Ainsi, Adolphe Karaimsky, immigré juif russe, artisan tailleur, arrivé à Paris en décembre 1903, choisit de nommer sa boutique "The Moderne Tailor», car, dans son métier, seul le « chic» anglais mesure la réussite ${ }^{5}$.

Les collages et montages d'images construisent également des récits d'artifice. Au sein des diasporas, dans les familles séparées par la migration, ils permettent de réunir fictivement le groupe et de le conforter en faisant circuler l'image entre ses différents ancrages. Ainsi, «Isidore Zeligman, à Paris depuis 1920, reçoit une photo de sa famille restée à Lodz en Pologne. Il demande alors à un photographe parisien de réaliser un montage afin d'y rajouter sa sœur à l'arrière-plan et lui-même et de rassembler ainsi, l'espace d'un cliché, toute la famille dispersée ${ }^{6} »$.

Enfin, et pour conclure, comment ne pas ignorer que ces photographies sont aussi - d'abord - l'œuvre de photographes étrangers? Krikor Djololian et Kasimir Zgorecki, que l'on découvre dans ce portfolio, tiennent la chronique l'un de l'exil arménien, l'autre des immigrés polonais installés dans le Nord. Mais leurs images se lisent aussi comme le récit de leur propre destinée. Chez Robert Capa, photographe de guerre et de légende, Hongrois de naissance, deux fois exilé, à Berlin, puis à Paris en 1933, ce jeu de miroirs prend d'autres formes, peut-être plus complexes. À travers l'inquiétude, la solitude et l'errance qui traversent son œuvre, dans la mélancolie qui accompagne son travail sur l'exil espagnol de 1939, il ne cesse de faire récit de sa propre histoire, récit caché, masqué par ses engagements, mais qui ressemble fort à l'autobiographie d'un homme jamais installé, qui fit de la photographie son seul pays.

Marianne Amar,

historienne, responsable du département de la recherche, Musée national de l'histoire de l'immigration.

\footnotetext{
4. Sur les petits commerçants dans l'entre-deux-guerres et la visibilité des origines, voir Claire Zalc, Melting Shops. Une histoire des commerçants étrangers en France, Paris, Perrin, 2010.

5. Nous nous référons ici à ses archives privées, conservées dans sa famille.

6. Nicole Priollaud, Victor Zeligman, Laurent Goldberg (dir.), Images de la mémoire juive. Immigration et intégration en France depuis 1880, Paris, Liana Levi/Mémoire juive de Paris, 1994, p. 64.
} 